\title{
Association of HCV Core Antigen Seropositivity with Long-Term Mortality in Patients on Regular Hemodialysis
}

\author{
Akihiko Kato $^{\text {a }}$ Takako Takita $^{\mathrm{b}}$ Mitsuyoshi Furuhashi ${ }^{\mathrm{b}}$ \\ Taiki Fujimoto $^{\text {b }}$ Hiroo Suzuki $^{\mathrm{b}}$ Yukitaka Maruyama $^{\mathrm{b}}$ \\ Yukitoshi Sakao ${ }^{a}$ Hiroaki Miyajima $^{c}$ \\ ${ }^{a}$ Blood Purification Unit and ${ }^{b}$ First Department of Medicine, Hamamatsu University School of \\ Medicine, and ${ }^{\mathrm{C}}$ Maruyama Hospital, Hamamatsu, Japan
}

\section{Key Words}

Hepatitis C $\cdot$ Persistent infection $\cdot$ Hemodialysis $\cdot$ Epidemiology $\cdot$ Mortality

\begin{abstract}
Anti-hepatitis $\mathrm{C}$ virus (HCV) antibody seropositivity is independently associated with poor prognosis in hemodialysis (HD) patients. However, anti-HCV antibody cannot distinguish between patients with active infection and those who have recovered from infection. We therefore aimed in this study to examine the association of HCV core antigen (HCVcAg) seropositivity with mortality in HD patients. We first measured serum HCVcAg using an immunoradiometric assay and anti-HCV antibody in 405 patients on regular HD, and followed them for 104 months. There were 82 patients (20.2\%) who had been positive for anti-HCV antibodies; 57 (69.5\%) of these were positive for HCVcAg. During the follow-up, 29 patients were excluded, so we tested the association of HCVcAg seropositivity with all-cause, cardiovascular (CV) and non-CV mortalities in 376 patients. A total of 209 patients (55.6\%) had expired during the observational period, 92 out of them due to CV causes. After adjusting for comorbid parameters, HCVcAg was independently associated with overall mortality (HR 1.61, 95\% Cl 1.05-2.47, $\mathrm{p}<0.05)$. HCV infection was significantly related to liver disease-related mortality. Past HCV infection also contributed to CV mortality (HR 2.63, 95\% Cl 1.27-5.45, p < 0.01). In contrast, anti-HCV antibody and HCVcAg seropositivities did not associate with infectious disease-related and cancer-related (expect for hepatocellular carcinoma) mortality. It follows from these findings that HCVcAg serology is associated with all-cause and CV mortality in HD patients.

Copyright $\odot 2012$ S. Karger AG, Basel
\end{abstract}




\section{Introduction}

The prevalence of hepatitis $\mathrm{C}$ virus (HCV) infection is much higher in hemodialysis (HD) patients than in the general population. The estimated prevalence of HCV infection (i.e., anti-HCV antibody positive) in dialysis patients was approximately $8 \%$ in the USA [1], $5 \%$ in Germany [2] and 10\% in Japan [3]. Standardized prevalence rates for anti-HCV antibody were 13-fold higher in men and 9-fold higher in women when compared with the population-based controls [4]. The incidence of new seroconversion of anti-HCV antibody occurred in about $1.0 \%$ of dialysis patients during the 1-year follow-up [3]. Outbreaks of incident HCV infection were also reported in at least 7 outpatient HD units during 1998-2008 in the USA [5].

$\mathrm{HCV}$ infection is usually diagnosed based on the detection of anti-HCV antibody, while it goes undetected in the first 4-6 weeks of infection (so-called 'window period'). Furthermore, patients positive for anti-HCV antibody include both those who are actively infected and those who have recovered from infection. Kidney Disease Improving Global Outcomes (KDIGO) clinical practice guidelines for the prevention, diagnosis, evaluation and treatment of hepatitis $\mathrm{C}$ in chronic kidney disease [6] recommended the use of nucleic acid test (NAT) either based on qualitative HCV RNA detection or HCV RNA quantification in units in high-prevalent settings. However, NAT is not suitable for routine screening as it is expensive and labor intensive.

Recently, measurement of HCV core antigen (HCVcAg) became clinically available using an immunoradiometric assay (IRMA) [7-10]. This test can detect total nucleocapsid core antigen whose sequence is highly conserved across HCV genotypes. The IRMA test has 96.4\% sensitivity and $100 \%$ specificity for qualitative HCV RNA detection in a communitybased general population [7]. In HD patients, this assay showed a sensitivity and specificity of 84 and $89 \%$, respectively [8]. These findings suggest that HCVcAg is applicable for clinical use as an alternative to NAT.

The aim of the present study was to evaluate in detail the association of chronic HCV infection with long-term mortality in HD patients in detail. We measured serum anti-HCV antibody and HCVcAg at the same time, and tested which causes of mortality are more likely to be associated with anti-HCV antibody and/or HCVcAg seropositivity in patients on maintenance HD.

\section{Patients and Methods}

\section{Patients}

We first enrolled 405 patients who had been undergoing regular HD in the two dialysis centers (Maruyama Hospital and Maruyama Clinic, Hamamatsu, Japan) in June 2002. This study was approved by the Ethics Committee of the institution, and informed consent was obtained from the patients.

All patients had been subjected to regular HD for $4-5 \mathrm{~h}$ three times per week at a blood flow rate of $180-250 \mathrm{ml} / \mathrm{min}$. All patients used bicarbonate dialysate $(30 \mathrm{mEq} / \mathrm{l}$; Kindaly AF2P, Fuso, Osaka, Japan) at a dialysate flow rate of $500 \mathrm{ml} / \mathrm{min}$. No bacteria or pyrogen was detected in the dialysate fluid obtained by reverse osmosis. Using an endotoxin removal filter, the endotoxin concentration in dialysate was below $0.050 \mathrm{EU} / \mathrm{ml}$ with a Limulus Amebocyte Lysate assay (Wako Junyaku endotoxin measurement kit, Tokyo, Japan).

\section{Blood Sampling and Laboratory Examinations}

Blood samples were drawn from the arterial site of the arteriovenous fistula at the start of a dialysis session after the 2-day interval. Serum electrolytes, urea nitrogen, creatinine, 
aspartate aminotransferase (AST), alanine aminotransferase (ALT), alkaline-phosphatase (Al-p), lactate dehydrogenase (LDH), albumin, cholesterol and triglyceride were measured by standard laboratory techniques using an autoanalyzer. Serum ferritin was measured by the latex agglutination method. Intact parathyroid hormone (PTH) was determined by immunoradiometric assay. C-reactive protein (CRP) was measured by latex photometric immunoassay (Wako Junyaku, Tokyo, Japan). We evaluated AST to platelet count ratio index (APRI), a non-invasive and sensitive marker of liver fibrosis in HD patients positive for antiHCV antibodies [11]. An APRI $<0.40$ has proved accurately to identify HD patients with liver fibrosis of stage $0-1$, while an APRI $\geq 0.95$ can estimate the presence of significant fibrosis in the liver biopsy samples [11].

Anti-HCV antibody test was performed by chemiluminescent enzyme immunoassay (EIA) using a third-generation assay (Ortho-Clinical Diagnostics, Emeryville, Calif., USA). Serum HCVcAg was measured by using IRMA (Ortho HCV antigen IRMA test, OrthoClinical Diagnostics). We also determined serum HCV RNA level by a quantitative RT-PCR assay kit (Amplicor GT HCV Monitor v2.0, Nippon Roche, Tokyo, Japan) in patients positive for anti-HCV antibody. The concentration of HCV RNA was expressed as KIU/ml, which ranges from 0.5 to $850 \mathrm{KIU} / \mathrm{ml}$. Serum samples with $<0.5 \mathrm{KIU} / \mathrm{ml}$ of HCV RNA were judged as negative. We also measured serum $\alpha$-fetoprotein (AFP) by a liquid phase-binding assay (Wako Junyaku, Osaka, Japan; normal range $<10 \mathrm{ng} / \mathrm{ml}$ ), protein-induced by vitamin $\mathrm{K}$ absence or antagonism (PIVKA-II) by an enzyme immunoassay with an anti-deoxycytidine triphosphate monoclonal antibody (Eisai Laboratory, Tokyo, Japan; normal range $<40 \mathrm{mAU} /$ $\mathrm{ml}$ ) and malondialdehyde (MDA) by spectrophotometry using thiobarbituric acid reactant (SRL, Tokyo, Japan) in anti-HCV antibody-positive patients.

\section{Follow-Up Study}

We followed 405 patients until February 2011 (for a total of 104 months). During the follow-up, information on kidney transplantation, hospital transfer, and survival prognosis was identified during outpatient follow-up visits or hospitalization in the two dialysis centers, by reviewing hospital records or by directly contacting the referring physicians.

\section{Statistical Analysis}

Values were expressed as means $\pm S D$. The $\chi^{2}$ test was used for categorical variables including gender and underlying kidney disease and seropositivity of anti-HCV antibody and HCVcAg. Differences between the two groups were analyzed by an unpaired Student test following the analysis of variance.

The primary outcome studied was overall mortality. Cardiovascular (CV), infectious disease-related, cancer-related [excluding hepatocellular carcinoma (HCC)], and liver disease-related mortalities were tested as a secondary outcome. Causes of CV death included the following: congestive heart failure (CHF), acute myocardial infarction (AMI), angina pectoris, cerebrovascular disease, ischemic intestinal diseases, peripheral artery disease (PAD), sudden death, fatal arrhythmia and other ischemic events. The causes of liver diseaserelated mortality included HCC and liver cirrhosis.

Survival rate was estimated using the Kaplan-Meier curves, and compared by using the log-rank test. Cox proportional hazards models were applied to calculate hazard ratio (HR) and adjusted survival curves for time to death, adjusting for age and gender (model 1), and further adjusting for DM, serum creatinine, albumin, phosphorous, total cholesterol, hemoglobin, log-transformed CRP, log-transformed ferritin and intact PTH (model 2). Results of the Cox proportional hazards analysis were presented as HR and the $95 \%$ confidence interval ( $95 \%$ CI). A p value $<0.05$ was considered statistically significant. All statistical calculations were performed with StatView 5J software (SAS Institute, Cary, N.C., USA). 
Table 1. Prevalence of anti-HCV antibody and HCVcAg positivities

\begin{tabular}{|c|c|c|c|}
\hline & $\mathrm{n}$ & $\begin{array}{l}\text { Anti-HCV antibody } \\
\text { positive, } n(\%)\end{array}$ & $\begin{array}{l}\text { HCVcAg } \\
\text { positive, n (\%) }\end{array}$ \\
\hline \multicolumn{4}{|c|}{ Age-specific prevalence } \\
\hline \multicolumn{4}{|c|}{ Age group } \\
\hline$<40$ years & 14 & $1(7.1)$ & $0(0)$ \\
\hline 40-49 years & 44 & $8(18.2)$ & $6(13.6)$ \\
\hline $50-59$ years & 89 & $24(27.0)$ & $20(22.5)$ \\
\hline $60-69$ years & 123 & $32(26.0)$ & $23(18.7)$ \\
\hline 70-79 years & 90 & $15(16.7)$ & $7(7.8)$ \\
\hline$\geq 80$ years & 45 & $2(4.4)$ & $1(2.2)$ \\
\hline Total & 405 & $82(20.2)$ & $57(14.1)$ \\
\hline \multicolumn{4}{|c|}{ HD vintage-related prevalence } \\
\hline \multicolumn{4}{|c|}{ Time on HD, years } \\
\hline$<1$ & 30 & $1(3.3)$ & $1(3.3)$ \\
\hline $1-2$ & 58 & $7(12.1)$ & $4(6.9)$ \\
\hline $3-4$ & 66 & $9(13.6)$ & $6(9.1)$ \\
\hline $5-9$ & 90 & $10(11.1)$ & $5(5.6)$ \\
\hline $10-14$ & 44 & $4(9.1)$ & $3(6.8)$ \\
\hline $15-19$ & 41 & $9(22.2)$ & $7(18.5)$ \\
\hline$\geq 20$ & 66 & $42(63.6)$ & $32(48.5)$ \\
\hline Total & 405 & $82(21.0)$ & $57(14.1)$ \\
\hline
\end{tabular}

$\mathrm{HCV}=$ Hepatitis C virus; $\mathrm{HCV}$ Ag $=\mathrm{HCV}$ core antigen.

\section{Results}

\section{Clinical Profiles}

The enrolled study population included 272 males and 133 females, with a mean age of 62 (19-96) years. The mean time on HD was 126 months, with a range of 1-394 months. The underlying kidney diseases were chronic glomerulonephritis $(\mathrm{n}=238)$, diabetic nephropathy $(n=76)$, polycystic kidney disease $(n=20)$, benign nephrosclerosis $(n=19)$, rapidly progressive glomerulonephritis $(n=5)$, lupus nephritis $(n=2)$, others $(n=12)$ and unknown $(n=33)$.

\section{Prevalence of Seropositivities for Anti-HCV Antibody and HCVcAg}

Table 1 shows the prevalence of anti-HCV antibody and HCVcAg according to 6 categories of age and 7 classifications of HD duration. The numbers of HD patients positive for anti-HCV antibody and HCVcAg were 82 (20.2\%) and 57 (14.1\%), respectively. There was no patient who was HCVcAg positive and HCV antibody negative.

A higher rate for anti-HCV antibody and HCVcAg was found in age categories of 50-59 and 60-69 years. Patients with HD vintage $>15$ years (especially $>20$ years) had increased rates for anti-HCV antibody and $\mathrm{HCVcAg}$.

\section{Comparison of Laboratory Data between Patients with and without HCVcAg}

Table 2 presents clinical characteristics of HD patients with or without anti-HCV antibody and/or HCVcAg. HCVcAg values ranged from 26 to 35,400 fmol/l. Time on HD was significantly longer in patients with anti-HCV antibody than in those without $(\mathrm{p}<0.01)$. However, there was no difference in HD vintage between patients with $\mathrm{HCVcAg}(\mathrm{n}=57)$ and those without $(\mathrm{n}=25)$. Serum AST and ALT were significantly higher in patients positive for HCVcAg than in those negative $(\mathrm{p}<0.01)$. The prevalence of ALT values $>28$ IU/l (upper normal limit for HD patients) [12] was significantly higher in patients positive for HCVcAg 
Table 2. Clinical characteristics of HD patients with or without anti-HCV antibody and/or HCVcAg

\begin{tabular}{|c|c|c|c|c|}
\hline & \multirow{2}{*}{$\begin{array}{l}\text { Anti-HCV } \\
\text { antibody (-)/ } \\
\text { HCVcAg (-) }\end{array}$} & \multicolumn{2}{|c|}{ Anti-HCV antibody $(+)$} & \multirow{2}{*}{$\begin{array}{l}\text { Anti-HCV } \\
\text { antibody (+) } \\
\text { HCVcAg (+) } \\
\text { versus }(-)\end{array}$} \\
\hline & & $\operatorname{HCVcAg}(+)$ & HCVcAg (-) & \\
\hline Patients, $\mathrm{n}$ & 323 & 57 & 25 & \\
\hline $\mathrm{HCV} c A g, \mathrm{fmol} / \mathrm{l}$ & $<20$ & $26-35,400$ & $<20$ & \\
\hline Age, years & $64 \pm 14$ & $60 \pm 8$ & $64 \pm 11$ & 0.14 \\
\hline HD vintage, months & $102 \pm 83$ & $232 \pm 121^{* *}$ & $189 \pm 124^{* *}$ & 0.14 \\
\hline Male/female & $219 / 114$ & $42 / 15$ & $16 / 9$ & 0.60 \\
\hline Diabetes, $\%$ & 19 & 16 & 29 & 0.39 \\
\hline \multicolumn{5}{|l|}{ Laboratory parameters } \\
\hline Creatinine, $\mathrm{mg} / \mathrm{dl}$ & $11.8 \pm 3.3$ & $11.8 \pm 2.5$ & $10.9 \pm 2.4$ & 0.13 \\
\hline Urea nitrogen, mg/dl & $73.4 \pm 15.3$ & $72.6 \pm 14.5$ & $68.3 \pm 17.4$ & 0.26 \\
\hline Calcium, mg/dl & $9.2 \pm 0.9$ & $9.6 \pm 1.0^{* *}$ & $9.3 \pm 0.7$ & 0.17 \\
\hline Phosphorous, mg/dl & $5.8 \pm 1.6$ & $6.0 \pm 1.2$ & $5.6 \pm 1.7$ & 0.19 \\
\hline AST, IU/1 & $14 \pm 18$ & $19 \pm 9^{*}$ & $13 \pm 8$ & $<0.01$ \\
\hline ALT, IU/1 & $11 \pm 19$ & $21 \pm 10^{* *}$ & $10 \pm 4$ & $<0.01$ \\
\hline Al-p, IU/l & $258 \pm 160$ & $283 \pm 144$ & $269 \pm 131$ & 0.69 \\
\hline LDH, IU/1 & $320 \pm 81$ & $325 \pm 62$ & $340 \pm 80$ & 0.34 \\
\hline Total cholesterol, mg/dl & $159 \pm 34$ & $143 \pm 31^{* *}$ & $149 \pm 41$ & 0.44 \\
\hline Triglyceride, mg/dl & $121 \pm 74$ & $108 \pm 68$ & $128 \pm 87$ & 0.26 \\
\hline Albumin, g/dl & $3.8 \pm 0.4$ & $3.8 \pm 0.3$ & $3.8 \pm 0.4$ & 0.95 \\
\hline Intact PTH, pg/ml & $328 \pm 339$ & $414 \pm 481$ & $215 \pm 177$ & $<0.05$ \\
\hline Ferritin, ng/ml & $178 \pm 191$ & $167 \pm 243$ & $142 \pm 121$ & 0.63 \\
\hline $\mathrm{Fe}, \mu \mathrm{g} / \mathrm{dl}$ & $57 \pm 24$ & $67 \pm 29 * *$ & $64 \pm 22$ & 0.59 \\
\hline TIBC, $\mu \mathrm{g} / \mathrm{dl}$ & $233 \pm 44$ & $259 \pm 42^{* *}$ & $227 \pm 37$ & $<0.01$ \\
\hline $\mathrm{CRP}, \mathrm{mg} / \mathrm{l}$ & $5.7 \pm 20.1$ & $1.7 \pm 2.3$ & $3.1 \pm 5.7$ & 0.11 \\
\hline White blood cells, / $\mu$ l & $6,160 \pm 2,030$ & $5,090 \pm 1,690^{* *}$ & $5,950 \pm 1,410$ & $<0.05$ \\
\hline Hemoglobin, g/dl & $10.4 \pm 1.1$ & $10.8 \pm 1.6^{*}$ & $10.4 \pm 1.7$ & 0.36 \\
\hline Platelets, $\times 10^{4} / \mu \mathrm{l}$ & $19.3 \pm 6.4$ & $14.8 \pm 4.7^{* *}$ & $19.5 \pm 6.7$ & $<0.01$ \\
\hline
\end{tabular}

There was no patient who was HCVcAg positive but not HCV antibody negative. HCV = Hepatitis C virus; $\mathrm{HCVcAg}=\mathrm{HCV}$ core antigen; $\mathrm{HD}=$ hemodialysis; $\mathrm{AST}=$ aspartate aminotransferase ALT = alanine aminotransferase; Al-p = alkaline-phosphatase; $\mathrm{LDH}=$ lactate dehydrogenase; $\mathrm{PTH}=$ parathyroid hormone; $\mathrm{Fe}=$ iron; $\mathrm{TIBC}=$ total iron binding capacity; $\mathrm{CRP}=\mathrm{C}$-reactive protein. ${ }^{* *} \mathrm{p}<0.01$ and ${ }^{*} \mathrm{p}<$ 0.05 versus the group of anti-HCV antibody-negative and HCVcAg-negative patients.

(28.1\%) than in those negative for HCVcAg while positive for anti-HCV antibody (3.0\%) and in those negative for both $(2.5 \%$; $\mathrm{p}<0.01)$. White blood cell and platelet counts were also significantly lower in patients with HCV core antigenemia when compared with those without $(\mathrm{p}<0.05$ and $\mathrm{p}<0.01$, respectively).

We measured serum HCV RNA in 69 out of 82 anti-HCV antibody-positive patients (table 3). Serum HCV RNA was detectable in 44 of 46 patients (95.6\%) who were positive for $\mathrm{HCV}$ cAg and in 4 of 23 negative patients (17.4\%).

In anti-HCV antibody-positive patients $(\mathrm{n}=82)$, there was no difference in serum AFP, PIVKA-II and MDA between HCVcAg-positive and -negative patients (table 3). In contrast, APRI was higher in patients with $\mathrm{HCVcAg}$ when compared with those without ( $\mathrm{p}<$ $0.01)$. 
Table 3. Comparison of HCV infection markers between anti-HCV antibody-positive patients with HCVcAg positivity and without

\begin{tabular}{llcr}
\hline & \multicolumn{2}{l}{ HCVcAg } & \multirow{2}{*}{$\mathrm{p}$ value } \\
\cline { 2 - 3 } & positive & negative & \\
\hline HCV RNA, kIU/ml & $316.0 \pm 218.2$ & $2.5 \pm 5.5$ & $<0.01$ \\
Positivity for HCV RNA $(>0.5 \mathrm{kIU} / \mathrm{ml})$ & $44 / 46(95.6 \%)$ & $4 / 23(17.4 \%)$ & $<0.01$ \\
AFP, ng/ml & $3.6 \pm 4.2$ & $2.4 \pm 1.4$ & 0.17 \\
PIVKA-II, $\mathrm{mAU} / \mathrm{ml}$ & $18 \pm 6$ & $18 \pm 7$ & 0.92 \\
MDA, $\mu \mathrm{mol} / \mathrm{l}$ & $2.8 \pm 0.6$ & $2.6 \pm 0.5$ & 0.18 \\
APRI & $1.51 \pm 1.08(0.25-6.13)$ & $0.78 \pm 0.63(0.25-1.27)$ & $<0.01$ \\
\hline
\end{tabular}

$\mathrm{HCV}=$ Hepatitis C virus; HCVcAg $=\mathrm{HCV}$ core antigen; AFP $=\alpha$-fetoprotein; PIVKA-II $=$ proteininduced by vitamin $\mathrm{K}$ absence or antagonism; $\mathrm{MDA}=$ malondialdehyde; APRI = AST to platelet count ratio index.

\section{Clinical Outcomes during the 104-Month Follow-Up}

Out of 405 patients, 23 patients had transferred to other dialysis institutes, and 6 patients also had received kidney transplantation during the follow-up. The prevalence of anti-HCV antibody seropositivity in these patients (24.1\%) was almost identical to that in the total patients (20.2\%). Thus, we tested the association of HCV seropositivity with survival prognosis in 376 patients (male/female $=260 / 116)$. The mean age was $64 \pm 13(22-96)$ years with a median HD time of 82 months (range 1-378). There were 75 patients (19.9\%) who had been positive for anti-HCV antibody and 52 of them also positive for HCVcAg.

During the follow-up, 209 (55.6\%) of the patients had expired, 92 (44.0\%) out of them due to $\mathrm{CV}$ causes. The causes of $\mathrm{CV}$ death were the following: $\mathrm{CHF}$ in 25 , sudden death in 19 , cerebral infarction in 17 , AMI in 9, intestinal ischemia in 7 , cerebral bleeding in 6 , arrhythmia in 4, angina pectoris in 3, and other reasons in 2 cases. Non-CV causes consisted of infectious diseases in 43 (pneumonia 22, sepsis 14, others 7), malignancies in 20 (lung cancer 4, HCC 3, blood disorder-related malignancy 3, renal cell carcinoma 2, others 8), uremia in 20, gastrointestinal bleeding in 6 , chronic obstructive pulmonary disease in 6 , liver cirrhosis in 4 , other reasons in 6 , and unknown reasons in 11 patients.

Kaplan-Meier estimation revealed that there was no significant difference in the cumulative mortality rate of total death in the patients positive for both anti-HCV antibody and HCVcAg $(67.3 \%, \mathrm{n}=52)$ and those positive for anti-HCV antibody while negative for HCVcAg $(69.6 \%, n=23)$, when compared with those without anti-HCV antibody $(53.5 \%$, $\mathrm{n}=301 ; \mathrm{p}=0.16$; fig. 1a). The crude mortality rates per 1,000 patient-years were $60.5 \mathrm{in}$ patients without anti-HCV antibody, 77.6 in those positive for anti-HCV antibody and $\mathrm{HCV} c \mathrm{Ag}$, and 80.2 in those only positive for anti-HCV antibody.

CV mortality rate was significantly higher in the patients seropositive for anti-HCV antibody but not for HCVcAg (43.5\%) compared to those seropositive for both anti-HCV antibody and HCVcAg (30.8\%) and those without anti-HCV antibody (21.9\%; p < 0.05; fig. 1b). The crude CV mortality rates per 1,000 patient-years were 25.3 in patients without anti-HCV antibody, 35.5 in those positive for anti-HCV antibody and HCVcAg, and 65.2 in those positive for anti-HCV antibody but not for $\mathrm{HCV} c \mathrm{Ag}$. In contrast, no difference was found in infectious disease-related and malignancy-related (excluding HCC) mortality among the 3 groups (fig. 1c, d).

There were 7 patients who had expired due to liver disease-related complications during the follow-up (HCC 4, liver cirrhosis 3). Five out of them were positive for HCVcAg, while 


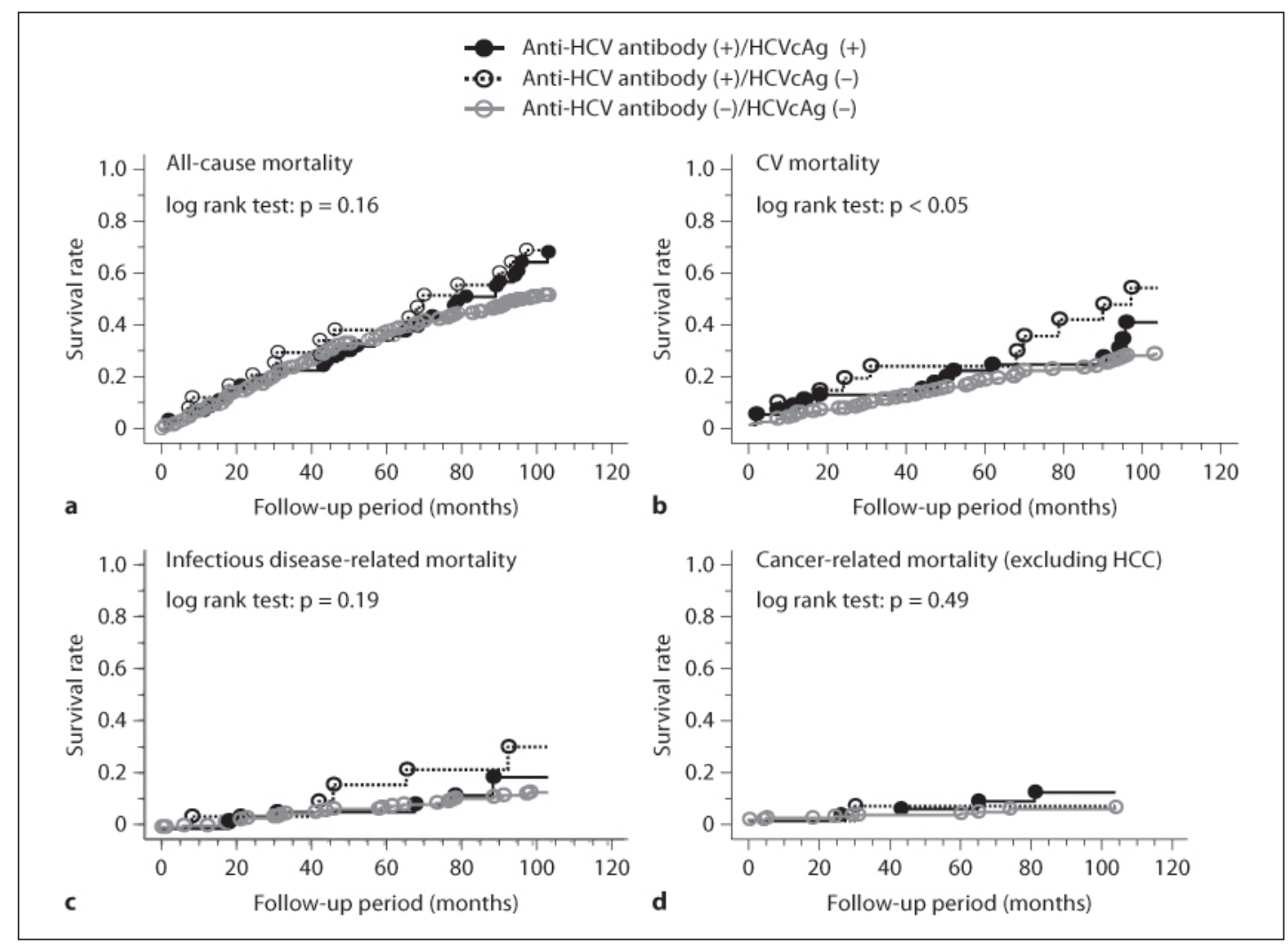

Fig. 1. Associations between HCV seropositivity and all-cause, CV, infectious disease-related and cancerrelated (excluding HCC) mortality. There was no significant difference in all-cause mortality rate during the 104-month follow-up among the 3 groups. However, CV death was more prominent in patients positive for anti-HCV antibody but negative for HCVcAg. No difference was found in infectious disease-related and cancer-related (excluding HCC) mortality in the 3 groups.

the others were negative for anti-HCV antibody. The crude mortality rates per 1,000 patientyears were 0.8 in patients without anti-HCV antibody, while they increased to 11.1 in those both positive for anti-HCV antibody and $\mathrm{HCV}$ cAg. There was no patient who had expired in those positive for anti-HCV antibody but not for HCVcAg.

\section{Predictors of Total, CV and Non-CV Mortalities (table 4)}

Cox regression analysis adjusted for age and gender (model 1) revealed that patients positive for anti-HCV antibody had a significantly higher risk for all-cause $(\mathrm{p}<0.01), \mathrm{CV}$ related $(\mathrm{p}<0.01)$ and liver disease-related mortality $(\mathrm{p}<0.01)$ when compared with those negative for anti-HCV antibody. Patients both positive for anti-HCV antibody and HCVcAg had a significantly higher risk for all-cause $(\mathrm{p}<0.01)$ and $\mathrm{CV}$-related death $(\mathrm{p}=0.03)$. Patients having anti-HCV antibody without $\mathrm{HCV} c A g$ had a significantly increased risk for $\mathrm{CV}$ death $(\mathrm{p}=0.02)$.

When further adjusted for co-morbid variables (model 2), anti-HCV antibody seropositivity was independently associated with a 1.61, 1.99, and 28.3-fold higher risk for total ( $\mathrm{p}<$ $0.01)$, CV-related $(\mathrm{p}=0.01)$ and liver disease-related death $(\mathrm{p}=0.01)$, respectively. There was also a significantly greater risk for total mortality $(\mathrm{p}=0.02)$ in patients with HCVcAg seropositivity. Anti-HCV antibody-positive patients without HCVcAg had a 2.63-fold higher risk for $\mathrm{CV}$ death $(\mathrm{p}<0.01)$. 
Table 4. Cox hazard analysis for all-cause, $\mathrm{CV}$ and non-CV mortalities during the follow-up

\begin{tabular}{|c|c|c|c|c|}
\hline & \multicolumn{2}{|l|}{ Model 1} & \multicolumn{2}{|l|}{ Model 2} \\
\hline & HR $(95 \%$ CI $)$ & $\mathrm{p}$ value & HR $(95 \%$ CI $)$ & $\mathrm{p}$ value \\
\hline \multicolumn{5}{|l|}{ All-cause mortality } \\
\hline Anti-HCV antibody (-) & 1.0 & & 1.0 & \\
\hline Anti-HCV antibody (+) & $1.63(1.18-2.25)$ & $<0.01$ & $1.68(1.12-2.32)$ & $<0.01$ \\
\hline $\operatorname{HCV} c A g(+)$ & $1.77(1.22-2.58)$ & $<0.01$ & $1.61(1.05-2.47)$ & 0.02 \\
\hline $\operatorname{HCVcAg}(-)$ & $1.40(0.84-2.35)$ & 0.20 & $1.61(0.92-2.83)$ & 0.10 \\
\hline \multicolumn{5}{|l|}{ CV mortality } \\
\hline Anti-HCV antibody (-) & 1.0 & & 1.0 & \\
\hline Anti-HCV antibody $(+)$ & $1.95(1.23-3.09)$ & $<0.01$ & $1.99(1.17-3.40)$ & 0.01 \\
\hline HCVcAg $(+)$ & $1.83(1.05-3.20)$ & 0.03 & $1.66(0.95-3.21)$ & 0.14 \\
\hline HCVcAg $(-)$ & $2.15(1.10-4.20)$ & 0.02 & $2.63(1.27-5.45)$ & $<0.01$ \\
\hline \multicolumn{5}{|c|}{ Infectious disease-related mortality } \\
\hline Anti-HCV antibody (-) & 1.0 & & 1.0 & \\
\hline Anti-HCV antibody $(+)$ & $1.90(0.97-3.75)$ & 0.06 & $1.91(0.89-4.09)$ & 0.10 \\
\hline $\operatorname{HCV} c A g(+)$ & $1.71(0.74-3.94)$ & 0.21 & $1.75(0.70-4.37)$ & 0.23 \\
\hline $\operatorname{HCV} c A g(-)$ & $2.25(0.87-5.82)$ & 0.09 & $2.22(0.73-6.69)$ & 0.16 \\
\hline \multicolumn{5}{|c|}{ Cancer-related mortality (excluding HCC) } \\
\hline Anti-HCV antibody (-) & 1.0 & & 1.0 & \\
\hline Anti-HCV antibody (+) & $1.95(0.67-5.65)$ & 0.22 & $2.29(0.65-8.03)$ & 0.19 \\
\hline $\operatorname{HCV} c A g(+)$ & $2.51(0.78-8.06)$ & 0.12 & $3.00(0.67-13.4)$ & 0.15 \\
\hline $\mathrm{HCV} c A g(-)$ & $1.06(0.14-8.17)$ & 0.96 & $1.43(0.17-12.3)$ & 0.75 \\
\hline \multicolumn{5}{|c|}{ Liver disease-related mortality } \\
\hline Anti-HCV antibody (-) & 1.0 & & 1.0 & \\
\hline Anti-HCV antibody $(+)$ & $11.3(2.17-58.3)$ & $<0.01$ & $28.3(2.10-282.1)$ & 0.01 \\
\hline HCVcAg $(+)$ & ND & & ND & \\
\hline $\operatorname{HCV} c A g(-)$ & ND & & ND & \\
\hline \multicolumn{5}{|c|}{$\begin{array}{l}\mathrm{CV}=\text { Cardiovascular; } \mathrm{HCV}=\text { hepatitis } \mathrm{C} \text { virus; } \mathrm{HCV} \mathrm{Ag}=\mathrm{HCV} \text { core antigen; } \mathrm{HR}=\text { hazards ratio; } \\
\mathrm{ND}=\text { not determined. We could not evaluate statistically whether } \mathrm{HCV} \text {; } \mathrm{Ag} \text { seropositivity is related to } \\
\text { liver disease-related mortality, since there was no death in the group positive for anti-HCV antibody while } \\
\text { negative for HCVcAg. }\end{array}$} \\
\hline
\end{tabular}

\section{Discussion}

Recently, HCVcAg quantification assay has proved useful for an early diagnosis of HCV infection in community-based [7] and in dialysis populations [8, 9]. HCVcAg may be an alternative to HCV RNA detection, since no subjects, who were negative for HCVcAg, were positive for HCV RNA in a large population-based cohort study [4]. In this study, based on the HCV RNA status as the gold standard, the sensitivity and the specificity of the IRMA assay were 95.6 and $82.6 \%$, respectively. These values are comparable to a previous study [8].

In a general population, patients who have recovered from HCV infection do not develop liver cirrhosis or HCC, while those with persistent HCV infection will develop serious complications over 20-30 years. So, information regarding HCV viremia is more important than that on the status of anti-HCV antibody. In this study, 57 (69.5\%) out of 82 patients with anti-HCV antibody positivity had detectable $\mathrm{HCV}$ Ag values. Especially, anti-HCV antibody-positive patients with $\mathrm{HD}$ vintage $>20$ years had a high prevalence of $\mathrm{HCVcAg}$ (76.2\%). A recent cohort study [4] also demonstrated that the seropositive rate for $\mathrm{HCVcAg}$ was $59.0 \%$ 
in HD patients positive for anti-HCV antibody. The study also showed that the HCVcAg seropositivity rate was $69.4 \%$ in patients with a longer dialysis period ( $\geq 15$ years). Taken together, these observations suggest that almost two thirds of anti-HCV antibody-positive HD patients have active HCV infection.

There are several observational studies that have shown an independent and significant association of anti-HCV-positive serologic status and poor prognosis in HD patients [12-20]. A recent meta-analysis of 7 cohorts including 11,589 HD patients estimated the overall adjusted relative risk of all-cause mortality to be 1.34 (95\% CI 1.13-1.59) for anti-HCV antibody-positive patients relative to anti-HCV antibody negative counterparts [21]. A nationwide database in the USA [17] demonstrated that the HR of total death during the 3-year follow-up was 1.25 (95\% CI 1.12-1.39) after adjusting for surrogates of the malnutrition-inflammation complex syndrome. Anti-HCV antibody seropositivity is also an independent predictor of a total mortality of 1 year with a relative risk of 1.37 (95\% CI 1.15-1.62) in Japan [18]. It has also been reported that HCV RNA positivity increased the risk of total death about 1.8-fold (95\% CI 1.01-3.14) when compared to non-viremic HD patients [12]. However, the main causes of death that increase mortality after chronic HCV infection remain to be fully determined.

Recently, Ohsawa et al. [20] reported that HCVcAg seropositivity independently contributes to increased risks for all-cause death in prevalent HD patients during the 5-year followup. In this study, we confirmed that HCV viremia detected by HCVcAg was significantly associated with all-cause mortality during the 104-month follow-up. In addition, the patients who had recovered from a past infection had a significantly higher risk for CV death. These findings suggest that $\mathrm{HCV}$ infection could increase all-cause and CV mortality in the long term. Kalantar-Zadeh et al. [22] also reported that anti-HCV antibody-positive patients younger than 65 years had a 1.8-fold higher risk for CV death.

Di Napoli et al. [16] first reported a greater risk for dying of liver or infectious causes in $\mathrm{HCV}$-positive compared with $\mathrm{HCV}$-negative $\mathrm{HD}$ patients in an observation period of 9 years (9.6 vs. 5.0\%, p <0.01). A meta-analysis [21], however, disclosed that liver disease death alone was more frequent in anti-HCV antibody-positive patients than in anti-HCV antibody-negative patients. A recent study also failed to detect any association of HCVcAg seropositivity with infectious disease-related death [20]. In the present study, we showed that the mortality rate due to liver disease was much higher in HCVcAg-positive patients. However, no association was found between HCV viremia and infectious disease-related and cancer-related mortality during the follow-up period, which is a comparable observation to that in the community-based cohort study [23].

$\mathrm{HCV}$ infection is associated with increases in inflammatory and oxidative stress markers in dialysis patients [24, 25]. In this study, however, there was no difference in serum CRP and MDA levels between $\mathrm{HCVcAg}$-positive and HCVcAg-negative patients at study entry. In addition, demographic or clinical features were almost identical between patients with and without HCV viremia in anti-HCV antibody-positive patients.

There are several limitations to this study. First, our study was limited in size and selectivity, comprising only $82 \mathrm{HCV}$-infected patients. Our study period (104 months) could be too short to attribute a direct effect of HCV seroconversion to death caused by liver disease. In addition, since we obviously studied a specific longevity group with a low prevalence of diabetes, our results may not be generally applicable. Second, we measured HCVcAg serology only on study entry, so there is a possibility that we missed occult HCV infection (i.e., only detectable HCV RNA in the liver or peripheral blood mononuclear cells). HD therapy itself may also change HCVcAg positivity, since a single session decreases serum $\mathrm{HCVcAg}$ titers by $24.4 \%$ [26]. Third, due to our insufficient database, we could not evaluate the impact of important risk factors such as blood pressure, body mass index, co-morbid conditions and 
socioeconomic status as explanatory variables. However, HCVcAg positivity is reported as an independent predictor of all-cause mortality even after the adjustment for these potent risk factors [20]. Finally, although the effect of interferon (IFN) therapy may have implications with respect to mortality rates in $\mathrm{HCVcAg}$-positive patients, information on treatment was limited. In this study, 2 patients had been treated with IFN during the follow-up period, while treatment had shortly ceased due to adverse effects.

In conclusion, we show that $\mathrm{HCVcAg}$ seropositivity is associated with a greater risk for overall mortality during the 104-month follow-up. Chronic HCV infection was related to liver disease-related mortality. In addition, the patients who had recovered from past infection had a 2.63-fold higher risk for CV death. In contrast, HCVcAg was not associated with death due to infectious disease and cancer, except for HCC. These findings suggest that detection of HCVcAg combined with anti-HCV antibody is useful in predicting long-term survival prognosis of persistent $\mathrm{HCV}$ infection in $\mathrm{HD}$ patients.

\section{Disclosure Statement}

No author had any conflicts of interest to disclose.

\section{References}

1 Finelli L, Miller JT, Tokars JI, et al: National surveillance of dialysis-associated diseases in the United States. Semi Dial 2005;18:52-61.

-2 Ross RS, Viazov S, Clauberg R, et al: Lack of de novo hepatitis $C$ virus infections and absence of nosocomial transmission of GB virus in a large cohort of German haemodialysis patients. J Viral Hepat 2009;16:230-238.

-3 Nakai S, Suzuki K, Masakane I, et al: Overview of regular dialysis treatment in Japan (as of 31 December 2008). Ther Apher Dial 2010;14:505-540.

-4 Ohsawa M, Kato K, Itai K, et al: Standardized prevalence ratios for chronic hepatitis $\mathrm{C}$ virus infection among adult Japanese hemodialysis patients. J Epidemiol 2010;20:30-39.

-5 Patel PR, Thompson ND, Kallen AJ, Arduino MJ: Epidemiology, surveillance, and prevention of hepatitis C virus infections in hemodialysis patients. Am J Kidney Dis 2010;56:371-378.

-6 KDIGO clinical practice guidelines for the prevention, diagnosis, evaluation, and treatment of hepatitis C in chronic kidney disease. Kidney Int 2008;73(suppl 109):S1-S99.

-7 Hayashi K, Hasuike S, Kusumoto K, et al: Usefulness of a new immuno-radiometric assay to detect hepatitis $C$ core antigen in a community-based population. J Viral Hepat 2005;12:106-110.

-8 Bouzgarrou N, Fodha I, Othman SB, et al: Evaluation of a total core antigen assay for the diagnosis of hepatitis C virus infection in haemodialysis patients. J Med Virol 2005;77:502-508.

-9 Fabrizi F, Lunghi G, Aucella F, et al: Novel assay using total hepatitis C virus (HCC) core antigen quantification for diagnosis of HCV infection in dialysis patients. J Clin Microbiol 2005;43:414-420.

10 Medhi S, Potukuchi SK, Polipalli SK, et al: Diagnostic utility of hepatitis C virus core antigen in hemodialysis patients. Clin Biochem 2008;41:447-452.

-11 Schiavon LL, Shiavon JLN, Filho G, et al: Simple blood tests as noninvasive markers of liver fibrosis in hemodialysis patients with chronic hepatitis C virus infection. Hepatology 2007;46:307-314.

-12 Stehman-Breen CO, Enerson S, Gretch D, Johnson RJ: Risk of death among chronic dialysis patients infected with hepatitis C virus. Am J Kidney Dis 1998;32:629-634.

-13 Pereira BJG, Natov SN, Bouthot BA, et al: Effect of hepatitis C infection and renal transplantation on survival in end-stage renal disease. Kidney Int 1998;53:1374-1381.

-14 Espinosa M, Martin-Malo A, Alvarez de Lara MA, Aljama P: Risk of death and liver cirrhosis in anti-HCV-positive long-term haemodialysis patients. Nephrol Dial Transplant 2001;16:1669-1674. 
15 Nakayama E, Akiba T, Marumo T, Sato C: Prognosis of anti-hepatitis C virus antibody-positive patients on regular hemodialysis therapy. J Am Soc Nephrol 2000;11:1896-1902.

-16 Di Napoli A, Pezzotti P, Di Lallo D, et al: Epidemiology of hepatitis C virus among long-term dialysis patients: a 9-year study in Italian region. Am J Kidney Dis 2006;48:629-637.

-17 Kalantar-Zadeh K, Kilpatrick RD, McAllister CJ, et al: Hepatitis C virus and death risk in hemodialysis patients. J Am Soc Nephrol 2007;18:1584-1593.

18 Johnson DW, Dent H, Yao Q, et al: Frequencies of hepatitis B and C infections among haemodialysis and peritoneal patients in Asia-Pacific countries: analysis of registry data. Nephrol Dial Transplant 2009;24:1598-1603.

-19 Scott DR, Wong JK, Spicer TS, et al: Adverse impact of hepatitis C virus infection on renal replacement therapy and renal transplant patients in Australia and New Zealand. Transplantation 2001;90: $1165-1171$.

20 Ohsawa M, Kato K, Tanno K, et al: Seropositivity for anti-HCV core antigen is independently associated with increased all-cause, cardiovascular, and liver disease related mortality in hemodialysis patients. J Epidemiol 2011;21:491-499.

-21 Fabrizi F, Takkouche B, Lunghi G, et al: The impact of hepatitis C virus infection on survival in dialysis patients: meta-analysis of observational studies. J Viral Hepat 2007;14:697-703.

-22 Kalantar-Zadeh K, McAllister CJ, Miller LG: Clinical characteristics and mortality in hepatitis Cpositive haemodialysis patients: a population based study. Nephrol Dial Transplant 2005;20:16621669.

-23 Ito H, Stuver SO, Hayashi K, et al: Increased rate of death related to presence of viremia among hepatitis $C$ virus antibody-positive subjects in a community-based cohort study. Hepatology 2009;50: 393-399.

24 Kato A, Odamaki M, Nakamura H, et al: Elevation of blood thioredoxin in hemodialysis patients with hepatitis C virus infection. Kidney Int 2003;63:2262-2268.

-25 Kalantar-Zadeh K, Miller LG, Daar ES: Diagnostic discordance for hepatitis C virus infection in hemodialysis patients. Am J Kidney Dis 2005;46:290-300.

-26 Mederacke I, Meier M, Luth JB, Schmidt-Gurtler H, et al: Different kinetics of HBV and HCV during haemodialysis and absence of seronegative viral hepatitis in patients with end-stage renal disease. Nephrol Dial Transplant 2011;26:2648-2656. 